\title{
Psychological Distress and Resilience in a Sample of Adolescents and Young Adults With Cancer During the COVID-19 Pandemic
}

\section{Clare Jacobson}

Guy's and St Thomas' NHS Foundation Trust

Nicola Miller

NHS Greater Glasgow and Clyde

Rebecca Mulholland

Sheffield Children's Hospital

\section{Laura Baker}

University Hospitals Bristol NHS Foundation Trust

\section{Daniel Glazer}

University College London

\section{Emily Betts}

Oxford University Hospitals NHS Trust

\section{Louise Brown}

Royal Cornwall Hospital Trust

\section{Vera Elders}

NHS Grampian

\section{Robert Carr}

Guy's and St Thomas' NHS Foundation Trust

\section{Olufunmilola Ogundiran}

Great Ormond Street Hospital for Children NHS Foundation Trust

Lee D Hudson ( $\nabla$ l.hudson@ucl.ac.uk)

Great Ormond Street Hospital for Children NHS Foundation Trust

\section{Research Article}

Keywords: Cancer, young adult, adolescent, psychological distress, mental health, resilience, COVID-19, SARS-CoV-2.

Posted Date: April 23rd, 2021

DOI: https://doi.org/10.21203/rs.3.rs-373545/v1 
License: (c) (i) This work is licensed under a Creative Commons Attribution 4.0 International License. Read Full License 
Psychological distress and resilience in a sample of Adolescents and Young Adults with cancer during the COVID-19 pandemic

Authors:

C Jacobson $^{1}$

N Miller ${ }^{2}$

R Mulholland ${ }^{3}$

L Baker $^{4}$

D Glazer ${ }^{5}$

E Betts $^{6}$

L Brown $^{7}$

V Elders ${ }^{8}$

R Carr ${ }^{1}$

L D Hudson $^{9}$

O Ogundiran ${ }^{9}$

${ }^{1}$ Guy's and St Thomas' NHS Foundation Trust.

${ }^{2} \mathrm{NHS}$ Greater Glasgow and Clyde.

${ }^{3}$ Sheffield Teaching Hospitals NHS Foundation Trust.

${ }^{4}$ University Hospitals Bristol NHS Foundation Trust.

${ }^{5}$ University College London Hospitals NHS Foundation Trust.

${ }^{6}$ Oxford University Hospitals NHS Foundation Trust.

${ }^{7}$ Royal Cornwall Hospitals NHS Trust.

${ }^{8} \mathrm{NHS}$ Grampian

${ }^{9} \mathrm{GOS}$ UCL Institute of Child Health 
Corresponding author : Lee D Hudson (I.hudson@ucl.ac.uk)

Key words: Cancer, young adult, adolescent, psychological distress, mental health, resilience, COVID-19, SARS-CoV-2.

\section{Abstract}

BACKGROUND: Adolescents and young people (AYA) with cancer are at greater risk of psychological distress which can impact treatment. COVID-19 has resulted in changes to cancer care delivery and AYA have been disproportionately affected by economic and educational effects of COVID-19, potentially impacting on mental health. Understanding the impact of COVID-19 on AYA with cancer is important to inform care.

METHODS: Online survey of 16-24 year olds receiving cancer treatment at 8 cancer centres in the UK in December 2020. We measured: self-perceived increased anxiety since COVID-19, impact of COVID-19 on treatment, life and relationships and used the 8-item Patient Health Questionnaire(PHQ-8), 7-item Generalised Anxiety Disorder Scale(GAD) and the 2-item Connor-Davidson Resilience Scale(CD-RISC).

RESULTS: 112 AYA participated (17.8\% of total eligible). $62.8 \%$ were female, $67.3 \%$ were 21 24 years. $83 \%$ were white. $59.8 \%$ had previously experienced mental health difficulties. $67.9 \%$ received cancer treatment during the pandemic and $33.9 \%$ were diagnosed during the pandemic. $78.6 \%$ reported COVID-19 having a significant impact on their life, $55.4 \%$ on their key relationship and $39.3 \%$ on their treatment. $79 \%$ reported experiencing some degree of increased anxiety since COVID-19.43.4\% had moderate-severe PHQ-8 scores and $37.1 \%$ for 
GADS-7. Self-report of impact on life was associated with greater anxiety during COVID-19 and moderate-severe PHQ-8 score (OR 3.64, 95\% Cl 2.52 to $19.40, \mathrm{p}<0.01$; OR $5.23,95 \% \mathrm{Cl}$ 1.65 to $16.56, p<0.01)$. Impact on relationships was associated with greater anxiety and moderate-severe GADS-7and PHQ-8 score (OR 2.89, 95\% $\mathrm{Cl} 1.11$ to 7.54, $\mathrm{p}=0,03$; OR 3.54, $95 \% \mathrm{Cl} 2.32$ to $15.17, \mathrm{p}<0.01 ; \mathrm{OR} 2.42,95 \% \mathrm{Cl} 1.11$ to $5.25, \mathrm{p}=0.03)$. Greater CD-RISC score was associated with lower risk of anxiety and mod-severe GADS-7and PHQ-8 scores (OR 0.58, $95 \% \mathrm{Cl} 0.41$ to $0.81, \mathrm{p}<0.01$; OR $0.5595 \% \mathrm{Cl} 0.4$ to $0.72, \mathrm{p}<0.01 ; \mathrm{OR} 0.52,95 \% \mathrm{Cl} 0.38$ to 0.69 , $\mathrm{p}<0.01)$

CONCLUSIONS: We found high levels of psychological distress in AYA with cancer, which is important knowledge for clinical teams working with this age group. Perceived impact of COVID-19 on relationships and life was predictive of poorer mental health, with resilience a potential protective factor.

\section{List of abbreviations}

AYA - adolescents and young adults

PHQ-8 - Patient Health Questionnaire

GADS-7 - 7-item Generalised Anxiety Disorder Scale

CDRS-2 - 2-item Connor-Davidson Resilience Scale

COVID-19 - SARS-CoV-2 pandemic

At the time of writing, the SARS-CoV-2 pandemic (COVID-19) has infected over 120 million people globally, and caused over 2.6 million deaths [1]. Though the highest risk factor for severe physical complications from SARS-CoV-2 infection in patients with cancer has been age, adolescents and young adults (AYA) with cancer have faced significant challenges as a 
result of the pandemic. As for many patients with cancer, care has been disrupted [2] and for some, initial presentations and diagnoses appear to have been delayed [3]. Concerns that AYA with cancer may be more at risk for severe complications of COVID-19, in particular those in treatment with immunocompromise [4], has led to some patients being advised to shield. Together with the broader population public health "lockdowns", this has potentially led to isolation and loneliness [5] and household income and food insecurity [6]. Indeed, AYA patients with cancer form part of age group who have been disproportionately affected by economic and educational impacts of "lockdowns" with potentially significant knock-on effects on mental health [7].

Cancer is an important health burden for AYA globally [8], and around 2500 16-24 year olds diagnosed with cancer per year in the United Kingdom (UK) [9]. As a group, AYA with cancer are known to have high levels of psychological distress compared to both healthy peers and older adult cancer patients $[10,11]$ as well as patients of a similar age with other medical conditions.[12] Psychological distress in AYA cancer patients is associated with both increased morbidity and reduced concordance with treatment regimes which can adversely affect quality of life and potentially prognosis $[13,14]$.

How the additional pressures during the SARS-CoV-2 pandemic may have impacted on the psychological wellbeing of AYA with cancer is therefore an important question, and one for which there is currently limited published data. A recent multi-disciplinary position paper has called for timely research to understand the effect of COVID-19 on mental health as well as better understanding possible risk and protective factors [15]. This information is needed urgently to inform current AYA cancer patient needs and appropriate service delivery in the 
context of the pandemic. We studied psychological wellbeing in AYA cancer patients in the UK during COVID-19 using a longitudinal online survey, and present complete baseline data here.

\section{Methods}

We recruited AYA patients who had received a cancer diagnosis between the ages of 16-24 years, and were currently engaged with cancer services at 8 UK centres to participate in an online study (Guy's and St Thomas' NHS Foundation Trust, London, University College London Hospitals NHS Foundation Trust, London, Sheffield Teaching Hospitals NHS Foundation Trust, Oxford University Hospitals NHS Foundation Trust, University Hospitals Bristol NHS Foundation Trust, Royal Cornwall Hospitals NHS Trust, NHS Grampian, Aberdeen and NHS Greater Glasgow and Clyde, Glasgow). Participants needed to have undergone treatment within the last 2 years. We included some patients aged up to 30 years (but diagnosed between 16-24 years) to capture those who were still on long initial treatment protocols and those who had relapsed. We used the online survey platform onlinesurveys (Jisc) with the survey open for 2 weeks from 9-23 ${ }^{\text {rd }}$ December 2020. Eligible patients were identified by local treatment teams and invited to take part in the survey via text message or email from a direct member of their NHS treating AYA team. The study is a longitudinal survey with 3 time points spanning 6 months, and currently only baseline data is available which we present here.

We asked participants to provide the demographics information on: current age group, age group at diagnosis, ethnicity, gender, eligibility in the past for free school meals (as a proxy for deprivation), living arrangements, diagnosis, treatment type and stage, whether they had 
been advised to shield, whether they were diagnosed or received active treatment during the pandemic, and whether they have a pre-existing mental health condition.

We used two validated self-report measures for psychological well-being (The 8-item patient health questionnaire (PHQ-8) and the 7-item Generalised Anxiety Disorder Scale (GADS-7)). The PHQ-8 has been established as a valid and reliable tool for assessing current depression in the general population and non-clinical settings $[16,17]$. Further, studies have demonstrated a good internal consistency (crohnbach alpha $=0.82$ ) in outpatient studies [17]. The eight items of the PHQ-8 each yield a score ranging from 0-3, providing a total severity score of $0-24$. The cut-offs for a score of moderate distress is a total raw score of 10-14, moderately severe $15-19$ and severe i20-24. The GADS-7 has also demonstrated high validity and reliability in the general population in assessing generalised anxiety disorder [18]. GADS-7 was also found as a reliable screening measure amongst cancer patients [19]. The seven items of the GADS-7 each yield a score ranging from 0-3, providing a total severity score of $0-21$. Total raw scores of 5, 10, and 15 represent cut-off points for mild, moderate, and severe anxiety, respectively. We asked participants to report whether they had experienced more, less or no change in anxiety since COVID-19 began. We also asked participants to respond to a series of statements using a 6-point Likert scale (strongly disagree, disagree, neither agree nor disagree, agree, strongly agree). Statements were: 1 ) overall, COVID-19 has had a significant impact on my life. 2) COVID-19 has made having or having had cancer/a brain tumour harder than it otherwise would have been. 3) COVID-19 has made me feel anxious about returning to hospital for appointments or treatment. 4) 
COVID-19 has had an impact on my treatment and/or care. 5) COVID-19 has had a significant impact on my key relationships.

We also used the 2-item Connor-Davidson Resilience Scale (CD-RISC) as a brief self-rating questionnaire of resilience. The CD-RISC has demonstrated good reliability and validity in a number of populations, which include a sample of cancer patients and a non-clinical sample of teenage and young adult students [20]. A total raw score ranging from 0-8 is yielded with a higher score indicating greater resilience.

Analyses were conducted using STATA (version 16). We reported summary descriptive data as proportions or averages (reported as means with standard deviations (SD) for normally distributed data and median and IQR for non-normally distributed data). We generated binary variables for: 1) Likert agreement statements divided into any degree of agreement versus any degree of no agreement, 2) GADS-7and PHQ-8 moderate to severe versus mild or none; 3) a little or a lot more anxious since COVID-19 versus same or less. We then used logistic regression models (thus reporting odd's ratios (OR) with 95\% confidence intervals) to test for associations between potential predictors of 1) GADS-7mod to severe, 2) PHQ-8 mod to severe and 3) more anxious since COVID-19. Multivariable logistic regression models were used to include variables found to have significant univariable associations.

The study received ethical approval by the London Central Health Research Authority and was approved within the Research and development departments at all eight NHS trusts.

\section{Results}


We recruited 112 participants from 628 eligible patients across the 8 centres at the time of the survey (17.8\%). Baseline participant characteristics are shown in table 1.

Table 1: Demographics and cancer specific information.

\begin{tabular}{|c|c|c|}
\hline & & $\begin{array}{l}\text { Percentage } \\
\text { (frequency) }\end{array}$ \\
\hline Gender & $\begin{array}{l}\text { Fe/male/non- } \\
\text { specific }\end{array}$ & $\begin{array}{l}62.8 / 32.7 / 2.7 \% \\
(71 / 37 / 3)\end{array}$ \\
\hline \multirow{3}{*}{$\begin{array}{l}\text { Current age } \\
\text { group }\end{array}$} & $16-19$ years & $18.6 \%(21)$ \\
\hline & $21-24$ years & $67.3 \%(76)$ \\
\hline & $25-30$ years & $13.3 \%(16)$ \\
\hline \multirow[t]{4}{*}{ Ethnicity } & White & $83 \%(93)$ \\
\hline & black or Asian & $8.9 \%(10)$ \\
\hline & Chinese & $0.9 \%(1)$ \\
\hline & mixed or other & $7.2 \%(8)$ \\
\hline $\begin{array}{l}\text { Eligibility for } \\
\text { free school } \\
\text { meals }\end{array}$ & Low SES & $15.9 \%(18)$ \\
\hline $\begin{array}{l}\text { Diagnosed } \\
\text { during covid }\end{array}$ & Yes/no & $\begin{array}{l}33.6 / 65.5 \% \\
(38 / 74)\end{array}$ \\
\hline $\begin{array}{l}\text { Active } \\
\text { treatment } \\
\text { during COVID- } \\
19\end{array}$ & Yes/no & $\begin{array}{l}67.3 \% / 31.0 \% \\
(76 / 35)\end{array}$ \\
\hline
\end{tabular}




\begin{tabular}{|c|c|c|}
\hline $\begin{array}{l}\text { Advised to } \\
\text { shield }\end{array}$ & $\begin{array}{l}\text { Yes/no/don't } \\
\text { know }\end{array}$ & $\begin{array}{l}68.1 / 15.9 / 15.0 \% \\
(77 / 18 / 17)\end{array}$ \\
\hline $\begin{array}{l}\text { Previous } \\
\text { psychological } \\
\text { treatment }\end{array}$ & Yes/no & $\begin{array}{l}60.2 / 39.8 \% \\
(67 / 45)\end{array}$ \\
\hline \multirow{10}{*}{$\begin{array}{l}\text { Diagnostic } \\
\text { group } \\
\%(n)\end{array}$} & Haematological & $49.1 \%(55)$ \\
\hline & Neurological & $13.5 \%(15)$ \\
\hline & Skin & $8.1 \%(9)$ \\
\hline & Head and neck & $7.1 \%(8)$ \\
\hline & Endocrine & $2.7 \%(3)$ \\
\hline & Urology & $4.5 \%(5)$ \\
\hline & Gynaecological & $2.7 \%(3)$ \\
\hline & Breast & $4.5 \%(5)$ \\
\hline & sarcoma & $4.5 \%(5)$ \\
\hline & other & $2.7 \%(3)$ \\
\hline $\begin{array}{l}\text { Diagnosed } \\
\text { during COVID }\end{array}$ & Yes / No (\%) & $\begin{array}{l}33.9 / 66.9 \% \\
(n=38 / 74)\end{array}$ \\
\hline \multirow{2}{*}{$\begin{array}{l}\text { Require } \\
\text { mental health } \\
\text { support prior } \\
\text { to cancer } \\
\text { diagnosis. }\end{array}$} & Yes & $\begin{array}{l}59.8 \% \\
(n=67)\end{array}$ \\
\hline & no & $40.2 \%(n=45)$ \\
\hline \multirow[t]{2}{*}{$\begin{array}{l}\text { COVID has } \\
\text { affected }\end{array}$} & agree & $39.6(44)$ \\
\hline & $\begin{array}{l}\text { neither agree } \\
\text { nor disagree }\end{array}$ & $27.9(31)$ \\
\hline
\end{tabular}




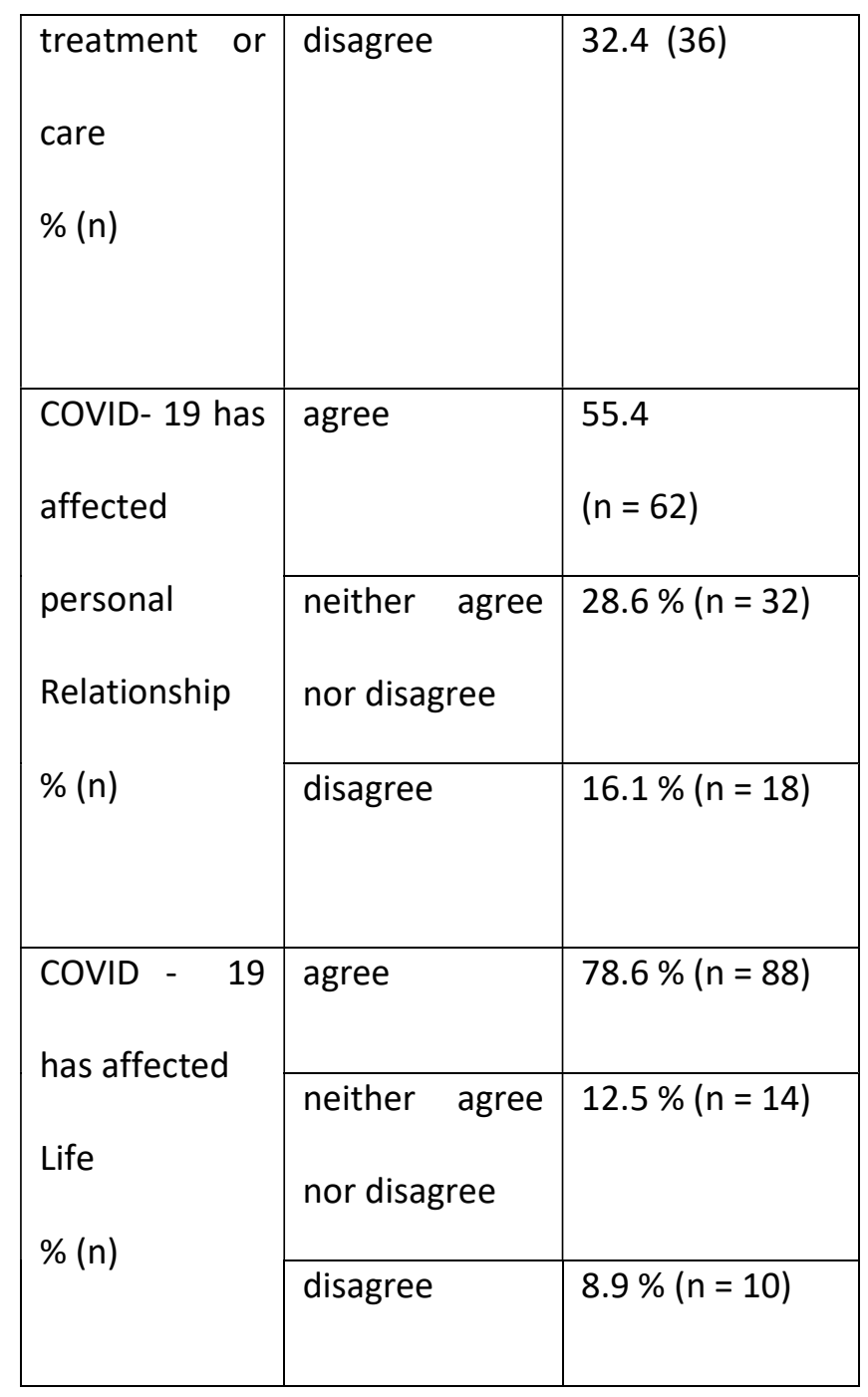

The sample contained a greater proportion of females $(n=71,62.8 \%)$ and the most common age group was $21-24$ years ( $n=76,67.3 \%) .18$ (15.9\%) of participants had been eligible for free school meals. Ethnicity was $83 \%$ white, $8.9 \%$ black or Asian, $0.9 \%$ Chinese and $7.2 \%$ mixed or other.

The main diagnostic groups were haematological, neurological, head and neck, and skin cancers (see table 1). $68.8 \%$ were advised to shield and $59.8 \%$ had previously experienced mental health difficulties requiring psychological input. $67.9 \%$ received cancer treatment during the pandemic and $33.9 \%$ were diagnosed during the pandemic. $78.6 \%$ reported COVID- 
19 having a significant impact on their life, 55.4\% on their key relationship and $39.3 \%$ on their treatment. Figure 1 shows $79 \%$ of the sample $(n=88)$ reported experiencing some degree of increased anxiety since COVID-19. $37.1 \%(n=42)$ scored in the moderate-severe range on the GADS-7 and $43.4 \%$ of the sample $(n=48)$ scored in the same range on the PHQ-8. $38.0 \%(n=43)$ reported that having cancer/brain tumour had given them skills to cope better with COVID19. $53.1 \%(n=59)$ reported that COVID-19 had made their experience of cancer/brain tumour harder. The median CD-RISC score was 6 (interquartile range 4-7). 
Figure 1: Graph showing proportions of participants for: A) degree of change in perceived anxiety since COVID19; B) cut-off for severity of GAD-7; C) cut-off for severity of PHQ-8; D) agreement that cancer/brain tumour has helped coping with COVID-19; and E) agreement that COVID-19 has made having cancer/brain tumour harder.

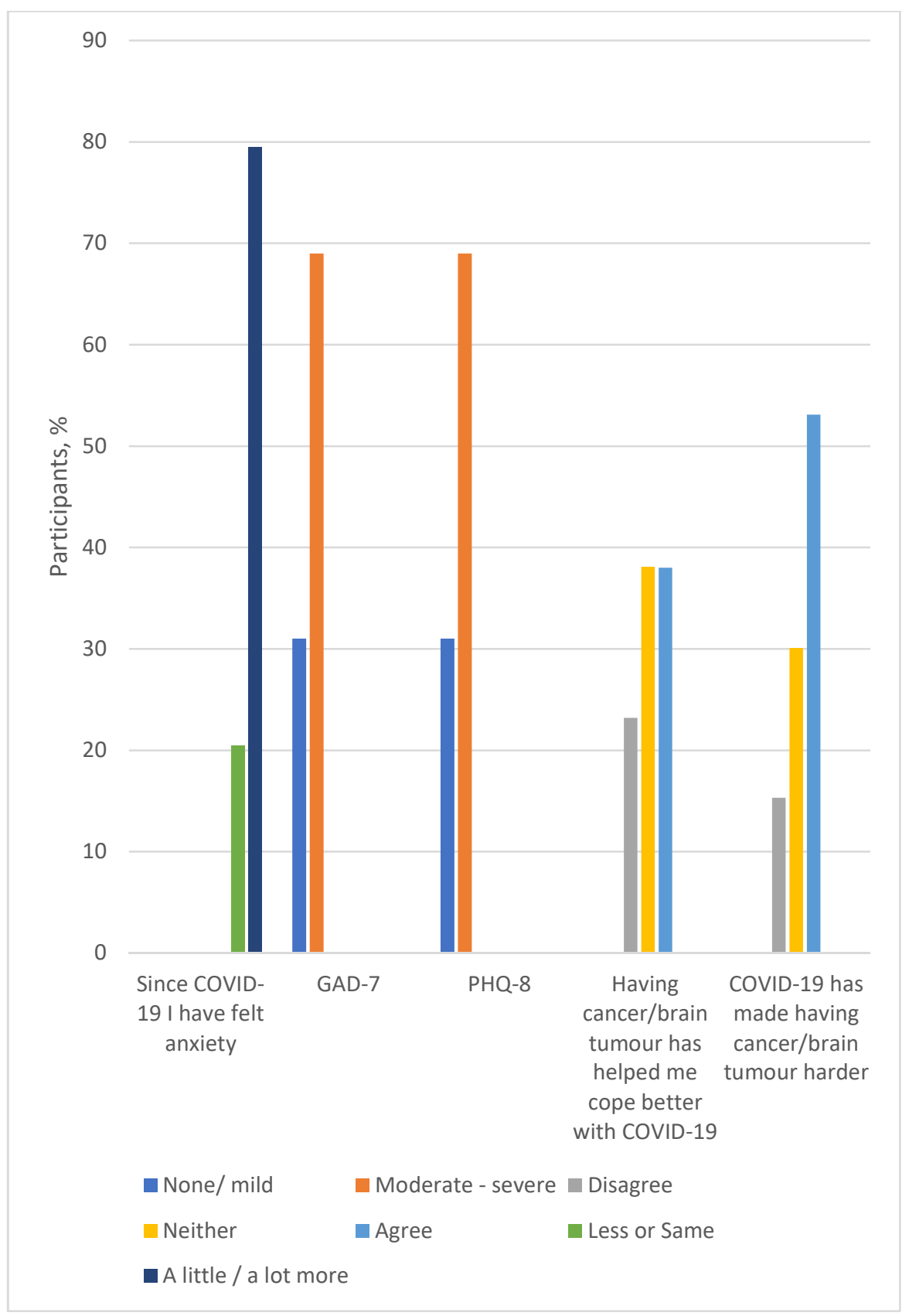


Univariable logistic regression models from the sample for predicting A) more anxiety since COVID-19 B) mod-severe GADS-7 score and c) mod-severe PHQ-8 score are shown in table 2.

Table 2: Univariable logistic regression of variables as predictors of A. little or more anxious than before COVID, B. A total GADS-7score indicating moderate or severe anxiety and C. A total GADS-7score indicating moderate or severe depression.

A. A little or more anxious than before COVID

\begin{tabular}{|c|c|c|c|c|c|}
\hline & & $\mathrm{n}$ & OR & $95 \% \mathrm{Cl}$ & $p$ \\
\hline \multirow{2}{*}{$\begin{array}{l}\text { Age group (vs. } \\
\text { 16-19 years) }\end{array}$} & $20-24$ years & \multirow[t]{2}{*}{112} & 2.73 & 0.94 to 7.82 & 0.06 \\
\hline & $25-30$ years & & 8.61 & 0.94 to 78.67 & 0.06 \\
\hline Gender & & 111 & 2.02 & 0.77 to 5.33 & 0.16 \\
\hline \multirow{2}{*}{$\begin{array}{l}\text { Ethnicity (vs. } \\
\text { white) }\end{array}$} & Asian & \multirow[t]{2}{*}{109} & 0.67 & 0.12 to 3.62 & 0.64 \\
\hline & Mixed & & 0.11 & 0.01 to 1.31 & 0.64 \\
\hline $\begin{array}{l}\text { Free school } \\
\text { meals }\end{array}$ & & 112 & 1.88 & 0.39 to 9.05 & 0.43 \\
\hline $\begin{array}{l}\text { Haematological } \\
\text { malignancy }\end{array}$ & & 111 & 0.97 & 0.38 to 2.49 & 0.96 \\
\hline $\begin{array}{l}\text { Active } \\
\text { treatment } \\
\text { during COVID }\end{array}$ & & 111 & 1.94 & 0.75 to 5.00 & 0.17 \\
\hline $\begin{array}{l}\text { Diagnosis } \\
\text { during COVID }\end{array}$ & & & 1.22 & 0.45 to 3.28 & 0.61 \\
\hline
\end{tabular}




\begin{tabular}{|c|c|c|c|c|}
\hline $\begin{array}{l}\text { Advised to } \\
\text { shield }\end{array}$ & 112 & 2.46 & 0.78 to 7.75 & 0.12 \\
\hline $\begin{array}{l}\text { COVID-19 has } \\
\text { made having or } \\
\text { having had } \\
\text { cancer harder }\end{array}$ & 111 & 20.3 & $4.45-92.43$ & $<0.01 *$ \\
\hline $\begin{array}{l}\text { Agree or } \\
\text { strongly agree } \\
\text { COVID has } \\
\text { impacted on } \\
\text { life }\end{array}$ & & 3.64 & 2.52 to 19.40 & $<0.01 *$ \\
\hline $\begin{array}{l}\text { Agree or } \\
\text { strongly agree } \\
\text { COVID has } \\
\text { impacted } \\
\text { treatment }\end{array}$ & 111 & 2.15 & 0.78 to 5.98 & 0.14 \\
\hline $\begin{array}{l}\text { Agree or } \\
\text { strongly agree } \\
\text { COVID has } \\
\text { impacted on } \\
\text { relationships }\end{array}$ & 112 & 2.89 & 1.11 to 7.54 & $0.03 *$ \\
\hline $\begin{array}{l}\text { Previous } \\
\text { mental health } \\
\text { difficulties }\end{array}$ & 112 & 1.85 & 0.73 to 4.67 & 0.19 \\
\hline Resilience & 112 & 0.58 & 0.41 to 0.81 & $<0.01 *$ \\
\hline
\end{tabular}


B. GADS-7score indicative of moderate or severe anxiety

\begin{tabular}{|c|c|c|c|c|c|}
\hline & & $\mathrm{n}$ & OR & $95 \% \mathrm{Cl}$ & $p$ \\
\hline \multirow{2}{*}{$\begin{array}{l}\text { Age group (v.s } \\
\text { 16-19 years) }\end{array}$} & $20-24$ years & \multirow[t]{2}{*}{112} & 1.45 & 0.53 to 4.01 & 0.47 \\
\hline & $25-30$ years & & 0.5 & 0.11 to 2.37 & 0.38 \\
\hline Gender & & 111 & 1.63 & 0.70 to 3.81 & 0.26 \\
\hline \multirow{2}{*}{$\begin{array}{l}\text { Ethnicity (vs } \\
\text { white) }\end{array}$} & Asian & \multirow[t]{2}{*}{109} & 0.50 & 0.10 to 2.63 & 0.42 \\
\hline & Mixed & & 0.76 & 0.07 to 8.65 & 0.82 \\
\hline $\begin{array}{l}\text { Free school } \\
\text { meals }\end{array}$ & & 112 & 0.86 & 0.29 to 2.54 & 0.79 \\
\hline $\begin{array}{l}\text { Haematological } \\
\text { malignancy }\end{array}$ & & 112 & 0.64 & 0.30 to 1.40 & 0.27 \\
\hline $\begin{array}{l}\text { Active } \\
\text { treatment } \\
\text { during COVID }\end{array}$ & & 111 & 1.18 & 0.51 to 2.73 & 0.70 \\
\hline $\begin{array}{l}\text { Diagnosis } \\
\text { during COVID }\end{array}$ & & 112 & 1.34 & 0.60 to 2.99 & 0.47 \\
\hline $\begin{array}{l}\text { Advised to } \\
\text { shield }\end{array}$ & & 112 & 2.11 & 0.63 to 7.04 & 0.22 \\
\hline $\begin{array}{l}\text { COVID-19 has } \\
\text { made having or } \\
\text { having had } \\
\text { cancer harder }\end{array}$ & & 111 & 2.56 & 1.13 to 5.74 & $0.02 *$ \\
\hline $\begin{array}{l}\text { Agree } \quad \text { or } \\
\text { strongly agree } \\
\text { COVID has }\end{array}$ & & 112 & 2.76 & 0.94 to 8.06 & 0.06 \\
\hline
\end{tabular}




\begin{tabular}{|c|c|c|c|c|c|}
\hline $\begin{array}{l}\text { impacted on } \\
\text { life }\end{array}$ & & & & & \\
\hline $\begin{array}{l}\text { Agree or } \\
\text { strongly agree } \\
\text { COVID has } \\
\text { impacted } \\
\text { treatment }\end{array}$ & & 111 & 1.32 & 0.60 to 2.90 & 0.48 \\
\hline $\begin{array}{l}\text { Agree or } \\
\text { strongly agree } \\
\text { COVID has } \\
\text { impacted on } \\
\text { relationships }\end{array}$ & & 112 & 3.54 & 1.54 to 8.16 & $<0.01^{*}$ \\
\hline $\begin{array}{l}\text { Previous } \\
\text { mental health } \\
\text { difficulties }\end{array}$ & & 112 & 5.93 & 2.32 to 15.17 & $<0.01$ \\
\hline Resilience & & 112 & 0.55 & 0.4 to 0.72 & $<0.01 *$ \\
\hline C. PHQ-8 s & core indicative & mode & ere $d \epsilon$ & & \\
\hline & & $\mathrm{n}$ & OR & $95 \% \mathrm{Cl}$ & $p$ \\
\hline Age group (vs. & 20-24 years & 112 & 1.89 & 0.69 to 5.22 & 0.22 \\
\hline 16-19 years) & $25-30$ years & & 1.0 & 0.99 & 0.25 to 4.07 \\
\hline Gender & & 111 & 1.43 & 0.63 to 3.21 & 0.39 \\
\hline $\begin{array}{l}\text { Ethnicity (vs } \\
\text { white) }\end{array}$ & $\begin{array}{l}\text { Asian } \\
\text { Mixed }\end{array}$ & 109 & $\begin{array}{l}0.39 \\
0.58\end{array}$ & $\begin{array}{l}0.07 \text { to } 2.02 \\
0.05 \text { to } 6.64\end{array}$ & $\begin{array}{l}0.26 \\
0.66\end{array}$ \\
\hline $\begin{array}{l}\text { Free school } \\
\text { meals }\end{array}$ & & 112 & 1.47 & 0.53 to 4.10 & 0.46 \\
\hline
\end{tabular}




\begin{tabular}{|c|c|c|c|c|}
\hline $\begin{array}{l}\text { Haematological } \\
\text { malignancy }\end{array}$ & 111 & 0.96 & 0.45 to 2.03 & 0.92 \\
\hline $\begin{array}{l}\text { Active } \\
\text { treatment } \\
\text { during COVID }\end{array}$ & 111 & 1.21 & 0.54 to 2.73 & 0.64 \\
\hline $\begin{array}{l}\text { Diagnosis } \\
\text { during COVID }\end{array}$ & 112 & 1.24 & 0.56 to 2.75 & 0.58 \\
\hline $\begin{array}{l}\text { Advised to } \\
\text { shield }\end{array}$ & 112 & 1.95 & 0.63 to 6.01 & 0.25 \\
\hline $\begin{array}{l}\text { COVID-19 has } \\
\text { made having or } \\
\text { having had } \\
\text { cancer harder }\end{array}$ & 111 & 2.5 & 1.14 to 5.45 & $0.02^{*}$ \\
\hline $\begin{array}{l}\text { Agree or } \\
\text { strongly agree } \\
\text { COVID has } \\
\text { impacted on } \\
\text { life }\end{array}$ & 112 & 5.23 & 1.65 to 16.56 & $<0.01 *$ \\
\hline $\begin{array}{l}\text { Agree or } \\
\text { strongly agree } \\
\text { COVID has } \\
\text { impacted } \\
\text { treatment }\end{array}$ & 111 & 1.00 & 0.46 to 2.15 & 0.99 \\
\hline $\begin{array}{l}\text { Agree or } \\
\text { strongly agree }\end{array}$ & 112 & 2.42 & 1.11 to 5.25 & $0.03 *$ \\
\hline
\end{tabular}




\begin{tabular}{|l|l|l|l|l|l|}
\hline COVID has & & & & \\
impacted on & & & & & \\
\hline Previous & & 112 & 5.92 & 2.46 to 14.26 & $<0.01$ \\
mental health & & & & & \\
\hline difficulties & & 112 & 0.52 & 0.38 to 0.69 & $<0.01^{*}$ \\
\hline
\end{tabular}

No significant associations were found between age group, gender, ethnicity or free school meals and increased anxiety, mod-severe GADS-7 or PHQ. There were no significant associations found between the most common type of cancer (haematological) and increased anxiety, moderate-severe GADS-7 or PHQ. Presence of previous mental health difficulties was associated with greater odds both moderate-severe GADS-7 and PHQ-8 scores (OR 5.93, 95\% $\mathrm{Cl} 2.32$ to $15.17, \mathrm{p}<0.01 ; \mathrm{OR} 5.92,95 \% \mathrm{Cl} 2.46$ to $14.26, \mathrm{p}<0.01$ respectively). Agreement that COVID-19 had impacted on life was associated with reporting being more anxious since COVID-19 and a moderate-severe PHQ-8 score (OR 3.64, 95\% Cl 2.52 to 19.40, p <0.01; OR $5.23,95 \% \mathrm{Cl} 1.65$ to $16.56, \mathrm{p}<0.01$ respectively) but not moderate to severe GADS-7score. Agreement that COVID-19 had impacted on relationships was associated with reporting being more anxious since COVID-19 and a moderate-severe GADS-7and PHQ-8 score (OR 2.89, 95\% Cl 1.11 to $7.54, p=0,03$; OR 3.54, 95\% Cl 2.32 to $15.17, p<0.01 ;$ OR $2.42,95 \% \mathrm{Cl} 1.11$ to 5.25 , $p=0.03)$. The association between COVID-19 affecting life and moderate to severe PHQ- 8 was robust when attenuated in a multivariable model with previous mental health difficulties (OR 5.31, $95 \% \mathrm{Cl} 1.58$ to $17.92, \mathrm{p}<0.01$ ). Associations between COVID-19 affecting relationships with both moderate-severe GADS-7and PHQ-8 were robust when attenuated in a 
multivariable model with previous mental health difficulties (OR $3.81,95 \% \mathrm{Cl} 1.55$ to $9.36, \mathrm{p}$ $<0.01$; OR $2.48,95 \% \mathrm{Cl} 1.06$ to $5.77, \mathrm{p}=0.04)$. There was a positive association between reporting that COVID-19 had made having or having had cancer harder with reporting being more anxious since COVID-19 and both moderate-severe GADS-7and PHQ-8 score (OR 20.3, $95 \% \mathrm{Cl} 4.45$ to $92.43, \mathrm{p}<0.01$; OR $2.56,95 \% \mathrm{Cl} 1.14$ to $5.72, \mathrm{p} 0.02 ; \mathrm{OR} 2.5,95 \% \mathrm{Cl} 1.14$ to $5.45, p=0.02$ respectively). Greater CD-RISC score was associated with lower odds of the reporting of being more anxious than before COVID-19, and with lower odds of both modsevere GADS-7and PHQ-8 scores (OR 0.58, 95\%Cl 0.41 to $0.81, \mathrm{p}<0.01$; OR $0.5595 \% \mathrm{Cl} 0.4$ to $0.72, \mathrm{p}<0.01 ;$ OR $0.52,95 \% \mathrm{Cl} 0.38$ to $0.69, \mathrm{p}<0.01$ )

\section{Discussion}

In our sample of AYA cancer patients from 8 centres in the UK, we found high levels of reported psychological distress, with around $80 \%$ of respondents reporting some degree of increased anxiety since the beginning of COVID-19, and around $40 \%$ meeting moderate to severe cut-offs on both the PHQ-8 and GADS-7 respectively. This is concerning given the known impact that psychological distress can have on cancer treatment in AYA with cancer [13]. We believe this to be the first study to examine for participants' own perception of COVID-19 impact on their treatment, lives and relationships. A majority of participants reported that COVID-19 had made a significant impact on their lives and their relationships, and had made their experience of cancer harder. Impact on life and relationships were found to be associated with psychological measures of depression and anxiety, in particular a reported impact on relationships associated with 3.5 odds of a moderate or severe GADS7scores and 2.5 odds of a severe or moderate PHQ-8 score. Perhaps not surprisingly, previous mental health difficulties were associated with high PHQ-8 and GADS-7 scores in our sample. 
However interestingly in analyses, when previous mental health difficulties were adjusted for, the relationship between impact on relationships and GADS-7 and PHQ-8 remained robust. We were surprised that neither active treatment during COVID-19 nor diagnostic group were associated with increased distress, however we lacked data on treatment modality and this warrants further investigation. Importantly, we found reduced odds of both a report of being more anxious since COVID-19 and both moderate to severe GADS-7and PHQ-8 scores with greater resilience scores (CD-RISC) which represents a potentially important moderator to be considered by clinicians.

Our findings are similar to those reported by Kosir et al [21] who early in the pandemic similarly used an online survey to examine depression and anxiety using the PHQ-4 item scale for depression and a 2-item scale for anxiety in 177 AYA cancer patients aged 18-39 years in Slovenia and the UK during the early stages of the pandemic in April 2020. A higher proportion of our sample reported greater anxiety since COVID-19 and a greater proportion reported significant distress and/or anxiety. Differences could be explained by the timepoint within the pandemic (April 2020 compared to December 2020 for our study). Casanova et al [22] found increased distress in a paediatric and AYA sample was related to perceived risk of severe complications from COVID-19 for their health. Our sample did not find an association between perceived impact of COVID-19 on healthcare but it did for perceived impact of COVID-19 on general life and relationships. One potential mechanism for how relationships for AYA with cancer may have been affected is that during the pandemic, family or significant others were usually unable to accompany AYAs for treatment or visit, and young people may have been separated by lockdown and shielding. This may have caused distress, longer-term relational effects and reducing 'connectedness'. Importantly, connectedness has been 
identified as a process that facilitates resilience [23], predicts young people's development of post-traumatic stress [24] and mediates psychological adjustment in young people with cancer [25]. The apparent protective effect of resilience for psychological distress in our sample is in keeping with the widely accepted concept that building patients' resilience with a cancer diagnosis is crucial in mediating the psychological distress and coping throughout the cancer experience [26]. The findings in our sample suggests resilience may have a role in moderating the effects for CYP by clinical teams in the current context of the pandemic, and further enforces the need for a preventative models of psychology [15] for young people with cancer [25].

Our study has a number of strengths and limitations. We used validated psychological questionnaires, alongside pragmatic questions to identify specific perceived impacts during COVID-19. There were a greater proportion of females in our sample and age group predominance was disproportionate (with the majority being aged 22-24). However, we deliberately recruited up to the age of 30 because whilst we were interested in AYA patients (16-24) we did not want to exclude data from patients who were diagnosed in this age group but continued treatment for a longer period or had relapsed. The proportion of AYA who reported being eligible for free school meals is similar to nationally reported rates $(13.6 \%$ in England[27]), suggesting representativeness of socio-economic status of the total population. We did not formally power our sample size, with the aim of recruiting as many AYA as possible. Though we recruited from 8 centres and targeted all eligible patients within those centres, our sample is small and less than $20 \%$ of eligible patients. This might have meant that our sample was not adequately powered to detect small effect sizes in univariable logistic regression models. The sample size also potentially leads to bias, in particular because AYA 
with higher levels of psychological difficulties may have been motivated to take part. Our sample is also cross-sectional and associations we have reported do not imply causation. Similarly, reported psychological measures may not have been temporally stable over time. That said, our study methodology is longitudinal and we will report at a future point on change over time.

\section{Conclusion}

Within the constraints of our sample size, we believe that the findings in our survey provides important information for care of AYA with cancer since the pandemic began. Our data suggests that the impact of COVID-19 on relationships and overall life may be predictive factors for poorer mental health in AYA with cancer and an area to explore with patients to look for potential solutions and opportunities is to enhance resilience as a possible protective factor.

\section{Declaration}

\section{Ethics approval and consent to participate}

The study received ethical approval by the London Central Health Research Authority (Committee's IRAS reference is 285244) and was approved within the Research and development departments at all eight NHS trusts. Informed consent was obtained from all participants. All methods were carried out in accordance with relevant guidelines and regulations.

\section{Consent for publication}


Although there is no identifiable data, informed consent to publish findings was obtained from all participants regardless.

\section{Availability of data and materials}

The data analysed during the current study are available from the corresponding author, Lee D Hudson, on request.

\section{Competing interests}

There are no competing interests.

\section{Funding}

Funding for the online platform was provided by the Teenage and Young Adult Cancer Charity Fund held by the Guy's and st Thomas' NHS Foundation trust charity.

\section{Author contributions}

C Jacobson conceived the idea, contributed to study design, supported the completion of the protocol, completed the ethical approval process, managed data entry, contributed to statistical analysis, completed the write-up and was a principle investigator at their site and oversaw participant recruitment.

N Miller conceived the idea, contributed to study design, completed the protocol, supported the ethical approval process and was a principle investigator at their site and oversaw participant recruitment. 
R Mulholland conceived the idea, contributed to study design, supported the completion of the protocol, supported the ethical approval process and was a principle investigator at their site and oversaw participant recruitment.

L Baker conceived the idea, contributed to study design, supported the completion of the protocol and supported the ethical approval process and was a principle investigator at their site and oversaw participant recruitment.

D Glazer was a principle investigator at their site and oversaw participant recruitment and edited the write-up.

E Betts was a principle investigator at their site and oversaw participant recruitment.

L Brown was a principle investigator at their site and oversaw participant recruitment and edited the write-up.

V Elders was a principle investigator at their site and oversaw participant recruitment.

R Carr supported the ethical approval process.

L D Hudson supported the ethical approval process, completed statistical analyses and significantly contributed to the write-up.

O Ogundiran completed data entry and literature searches.

\section{Acknowledgements}

We would like to acknowledge and thank the young people who took part in the survey and the staff at individual cancer centres who supported the survey and its communication to eligible participants. In particular, we would like to thank Gavin Maynard-Wyatt, Hannah Lind, Nicola Clapson, Amanda Copland and Louise Morris. 


\section{References}

1. WHO Coronavirus (COVID-19) Dashboard [https://covid19.who.int] (last accessed $2932020)$

2. Kutikov A, Weinberg DS, Edelman MJ, Horwitz EM, Uzzo RG, Fisher RI: A War on Two Fronts: Cancer Care in the Time of COVID-19. Ann Intern Med 2020, 172(11):756758.

3. Kaufman HW, Chen Z, Niles J, Fesko Y: Changes in the Number of US Patients With Newly Identified Cancer Before and During the Coronavirus Disease 2019 (COVID19) Pandemic. JAMA Netw Open 2020, 3(8):e2017267.

4. Belsky JA, Tullius BP, Lamb MG, Sayegh R, Stanek JR, Auletta JJ: COVID-19 in immunocompromised patients: A systematic review of cancer, hematopoietic cell and solid organ transplant patients. The Journal of infection 2021, 82(3):329-338.

5. Loades ME, Chatburn E, Higson-Sweeney N, Reynolds S, Shafran R, Brigden A, Linney C, McManus MN, Borwick C, Crawley E: Rapid Systematic Review: The Impact of Social Isolation and Loneliness on the Mental Health of Children and Adolescents in the Context of COVID-19. Journal of the American Academy of Child and Adolescent Psychiatry 2020, 59(11):1218-1239.e1213.

6. Morales DX, Morales SA, Beltran TF: Racial/Ethnic Disparities in Household Food Insecurity During the COVID-19 Pandemic: a Nationally Representative Study. J Racial Ethn Health Disparities 2020:1-15.

7. Ganson KT, Tsai AC, Weiser SD, Benabou SE, Nagata JM: Job Insecurity and Symptoms of Anxiety and Depression Among U.S. Young Adults During COVID-19. The Journal of adolescent health : official publication of the Society for Adolescent Medicine 2021, 68(1):53-56.

8. Fidler MM, Gupta S, Soerjomataram I, Ferlay J, Steliarova-Foucher E, Bray F: Cancer incidence and mortality among young adults aged 20-39 years worldwide in 2012: a population-based study. The lancet oncology 2017, 18(12):1579-1589.

9. Cancer Research UK. Cancer incidence by age. [https://www.cancerresearchuk.org/health-professional/cancerstatistics/incidence/age] (last accessed 293 2020)

10. Barnett M, McDonnell G, DeRosa A, Schuler T, Philip E, Peterson L, Touza K, Jhanwar $S$, Atkinson TM, Ford JS: Psychosocial outcomes and interventions among cancer survivors diagnosed during adolescence and young adulthood (AYA): a systematic review. J Cancer Surviv 2016, 10(5):814-831.

11. Kosir U, Wiedemann M, Wild J, Bowes L: Psychiatric disorders in adolescent cancer survivors: a systematic review of prevalence and predictors. Cancer Reports 2019, 2(3):e1168.

12. MCDANIEL JS, Musselman DL, Nemeroff CB: Cancer and depression: theory and treatment. Psychiatric Annals 1997, 27(5):360-364.

13. Park EM, Rosenstein DL: Depression in adolescents and young adults with cancer. Dialogues Clin Neurosci 2015, 17(2):171-180.

14. Zebrack B, Mathews-Bradshaw B, Siegel S: Quality cancer care for adolescents and young adults: a position statement. Journal of clinical oncology : official journal of the American Society of Clinical Oncology 2010, 28(32):4862-4867.

15. Holmes EA, O'Connor RC, Perry VH, Tracey I, Wessely S, Arseneault L, Ballard C, Christensen $\mathrm{H}$, Silver RC, Everall I: Multidisciplinary research priorities for the 
COVID-19 pandemic: a call for action for mental health science. The Lancet Psychiatry 2020.

16. Kroenke K, Strine TW, Spitzer RL, Williams JBW, Berry JT, Mokdad AH: The PHQ-8 as a measure of current depression in the general population. J Affect Disord 2009, 114(1):163-173.

17. Pressler SJ, Subramanian U, Perkins SM, Gradus-Pizlo I, Kareken D, Kim J, Ding Y, Sauvé MJ, Sloan R: Measuring Depressive Symptoms in Heart Failure: Validity and Reliability of the Patient Health Questionnaire-8. Am J Crit Care 2011, 20(2):146152.

18. Spitzer RL, Kroenke K, Williams JBW, Löwe B: A Brief Measure for Assessing Generalized Anxiety Disorder: The GAD-7. Arch Intern Med 2006, 166(10):10921097.

19. Esser $\mathrm{P}$, Hartung TJ, Friedrich $\mathrm{M}$, Johansen $\mathrm{C}$, Wittchen $\mathrm{H}-\mathrm{U}$, Faller $\mathrm{H}$, Koch $\mathrm{U}$, Härter M, Keller M, Schulz H et al: The Generalized Anxiety Disorder Screener (GAD-7) and the anxiety module of the Hospital and Depression Scale (HADS-A) as screening tools for generalized anxiety disorder among cancer patients. Psychooncology 2018, 27(6):1509-1516.

20. Markowitz S, Peters ML: Psychometrische evaluatie van de CD-Risc in een Nederlandstalige populatie: een multi-of unifactorieel meetinstrument om veerkracht te meten. Tijdschr Klin Psychol 2014, 44(1):55-68.

21. Košir U, Loades M, Wild J, Wiedemann M, Krajnc A, Roškar S, Bowes L: The impact of COVID-19 on the cancer care of adolescents and young adults and their well-being: Results from an online survey conducted in the early stages of the pandemic. Cancer 2020, 126(19):4414-4422.

22. Casanova M, Pagani Bagliacca E, Silva M, Patriarca C, Veneroni L, Clerici CA, Spreafico $F$, Luksch $R$, Terenziani $M$, Meazza $C$ et al: How young patients with cancer perceive the COVID-19 (coronavirus) epidemic in Milan, Italy: Is there room for other fears? Pediatr Blood Cancer 2020, 67(7):e28318.

23. Fergus S, Zimmerman MA: Adolescent resilience: A framework for understanding healthy development in the face of risk. Annu Rev Public Health 2005, 26:399-419.

24. McDermott B, Berry H, Cobham V: Social connectedness: a potential aetiological factor in the development of child post-traumatic stress disorder. Aust $N Z \mathrm{~J}$ Psychiatry 2012, 46(2):109-117.

25. Barber BK, Schluterman JM: Connectedness in the lives of children and adolescents: A call for greater conceptual clarity. Journal of Adolescent Health 2008, 43(3):209216.

26. Patterson P, Hardman F, Cheshire J, Sansom-Daly U: Balancing Risk with Resilience: Using Holistic Psychosocial Screening and Assessment Tools Effectively with Adolescents and Young Adults with Cancer. In: Nursing Adolescents and Young Adults with Cancer. edn.: Springer; 2018: 95-119.

27. Department of Education. Schools, pupils and their characteristics: January 2018. https://www.gov.uk/government/statistics/schools-pupils-and-their-characteristicsjanuary-2018 (last accessed 293 2020) 
Figures

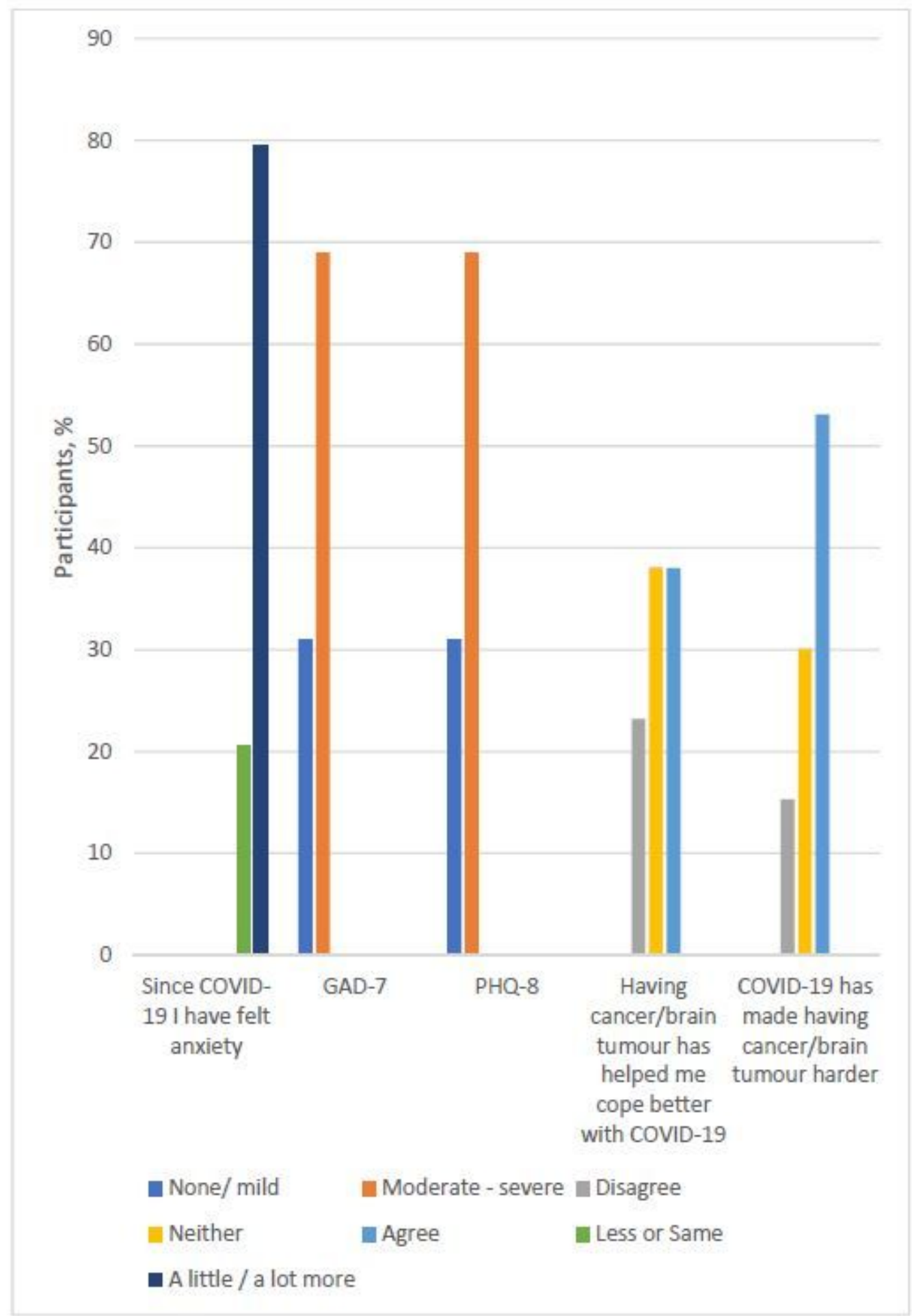

\section{Figure 1}

Graph showing proportions of participants for: A) degree of change in perceived anxiety since COVID-19; B) cut-off for severity of GAD-7; C) cut-off for severity of PHQ-8; D) agreement that cancer/brain tumour 
has helped coping with COVID-19; and E) agreement that COVID-19 has made having cancer/brain tumour harder. 